\title{
Knowledge and practice of cervical cancer screening in general population and medical personnel: A gap to be bridged
}

\author{
Ritu Khatuja' ${ }^{1}$, Shweta Mittal' ${ }^{2}$, Unnati Asthana ${ }^{3}$, Menka Verma $^{4}$, Mini Kadian $^{5}$ \\ ${ }^{1}$ Assistant Professor, ${ }^{2,5}$ Senior Resident, Department of Obstetrics and Gynaecology, Baba Saheb Ambedkar Medical \\ College and Hospital, Rohini, Delhi, ${ }^{3}$ Assistant Professor, Department of Anesthesia, ESIC Dental College and \\ Hospital, New Delhi, ${ }^{4}$ Assistant Professor, Department of Obstetrics and Gynaecology, Pandit Bhagwat Dayal Sharma \\ Post Graduate Institute of Medical Sciences, Rohtak, Haryana, India
}

Background: Carcinoma cervix is a leading cause of morbidity and mortality among women worldwide. Early diagnosis is quite beneficial as it has a long precancerous state. It is important to have a knowledge regarding the natural course of the disease and the screening methods. Aims and Objectives: This study was conducted to evaluate the knowledge, attitude, and practice among women attending the outpatient department (OPD) and medical personnel. Materials and Methods: The present cross-sectional study was carried out on 240 women, out of which 120 women were taken randomly from the OPD and 120 women were the medical personnel (doctors and nurses) of the hospital. After obtaining written informed consent from the women, a structured questionnaire was administered to collect the information. Results: The knowledge and awareness of carcinoma cervix and its screening was $32.5 \%$ in the women of general population and $100 \%$ in the medical personnel, whereas the percentage of women undergoing the actual screening was $25 \%$ in general population and $17.5 \%$ in medical personnel. The hindrance of practice in general population was lack of knowledge, but in medical personnel, it was due to hesitation, embarrassment, lack of time, and lack of positive motivation. Conclusion: There was a wide discrepancy in the knowledge of cervical cancer and the actual screening practices, not only in the general population but also among the medical personnel. To bridge this gap, effective information, education and communication strategies are required in both the groups to alleviate the morbidity and mortality of this grim disease.
Access this article online Website: http://nepjol.info/index.php/AJMS DOI: 10.3126/ajms.v13i2.40582 E-ISSN: 2091-0576 P-ISSN: 2467-9100

Copyright (c) 2022 Asian Journal of Medical Sciences

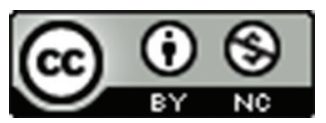

This work is licensed under a Creative Commons Attribution-NonCommercial 4.0 International License.

Key words: Attitude; Cervical cancer; Knowledge; Pap test; Practices

\section{INTRODUCTION}

Carcinoma cervix is the leading cause of morbidity and mortality among women across the world and India. Worldwide cancer cervix affects about 16/100,000 women per year and kills about 9/100,000 per year globally. Developing countries account for $85 \%$ of the estimated burden. ${ }^{1-3}$ The current estimates indicate approximately 132,000 new cases diagnosed and 74,000 deaths annually in India, accounting to nearly $1 / 3^{\text {rd }}$ of the global cervical cancer deaths. ${ }^{1}$
Cervical cancer is a slow growing disease and women generally manifest in later stages of the disease when chances of survival are lower. ${ }^{4}$ Virtually all cases of cervical cancer are attributable to persistent infection by certain strains of human papilloma virus (HPV) especially HPV-16 and HPV-18 and it can take 20 years to develop the carcinoma cervix. ${ }^{2,5}$ The other known risk factors for cervical cancer include early onset of sexual activities, multiple sex partners, long use of oral contraceptives, immunosuppressants, smoking and specific dietary factors. Thus, slow growing nature of cancer, known etiology, other 
modifiable cause, and availability of preventive vaccination make it a preventable malignancy.

The methods of prevention are known since long. Despite the availability of cervical cancer screening facilities (Pap test) as preventive measure at free of cost, the burden of cervical cancer presenting in advanced stages of the disease is very high in India. It is due to poor utilization of these services, as women have poor knowledge and attitude. This aspect is important not only for the general population but also for the medical professionals as they play a key role in imparting awareness regarding prevention and treatment. Hence, this study was conducted to assess the knowledge, attitude, and practice (KAP) regarding cervical cancer screening among women of general population and medical profession.

\section{Aims and objectives}

Aim of the study was to evaluate the KAP among women attending the outpatient department (OPD) and medical personnel.

\section{MATERIALS AND METHODS}

This cross-sectional study was carried out in a tertiary care hospital in New Delhi. A total of 240 women were included in the study, out of which 120 women were taken randomly from the OPD and 120 women were the medical personnel (doctors and nurses) of the hospital. After obtaining written informed consent from the women, a structured questionnaire was administered to collect the information regarding KAPs. Knowledge was assessed based on information about carcinoma cervix, its risk factors, knowledge about preventable nature of the disease, screening tests and any vaccination available. If the women had not heard about the carcinoma cervix, it was considered as zero knowledge. If they answered one question, it was considered poor knowledge. If they answered two questions, it was considered average knowledge. If three questions were answered, it was considered good knowledge, and if more than three questions were answered, it was considered very good knowledge. Attitude was assessed based on whether they were willing for screening or not. Practice was assessed based on whether the women underwent cervical cancer examination and not.

\section{RESULTS}

Majority of the women in general population were in the age group of 21-25 years and those in medical personnel group were in the age group of 26-30 years. Majority of the women were married in both the groups. While the most women from the general population were from the lower socioeconomic strata, subjects in the medical personnel group belonged to middle class. As far as education status was concerned, 73\% of general population women had education below higher secondary certificate and $33 \%$ were illiterate, while all women were graduates in the medical personnel group. In terms of working, $70 \%$ of the general population women were nonworking and all were working in the medical personnel group where $76.7 \%(\mathrm{n}=92)$ of women were doctors and the rest $(\mathrm{n}=28)$ being the nurses (Table 1).

It was observed that in general population group, 92.5\% $(\mathrm{n}=81)$ women had no/poor knowledge whereas rest $7.5 \%$ had average/good knowledge. In medical personnel group, none of them had zero/poor knowledge and average/good knowledge was present in $41.2 \%$ (Table 2).

There was lack of practice in both the group. In general population group, $75 \%(\mathrm{n}=90)$ women never underwent screening and in medical personnel group, $82.5 \%(\mathrm{n}=99)$ women never underwent screening. This difference was not statistically significant $(\mathrm{P}=0.155)$. HPV vaccination was received by approximately two percent of general population women and $18 \%$ of medical personnel women (Table 3 ).

\begin{tabular}{|c|c|c|}
\hline Variables & $\begin{array}{c}\text { General population } \\
(n=120)(\%)\end{array}$ & $\begin{array}{c}\text { Medical personnel } \\
(n=120)(\%)\end{array}$ \\
\hline \multicolumn{3}{|l|}{ Age (years) } \\
\hline $21-35$ & $82(68.3)$ & $84(70)$ \\
\hline $36-45$ & $28(23.3)$ & $29(24.2)$ \\
\hline$>45$ & $10(8.4)$ & $7(5.8)$ \\
\hline \multicolumn{3}{|l|}{ Marital status } \\
\hline Married & 104 (86.7) & $68(56.7)$ \\
\hline Unmarried & $16(13.3)$ & 52 (43.3) \\
\hline \multicolumn{3}{|l|}{$\begin{array}{l}\text { Educational } \\
\text { status }\end{array}$} \\
\hline Illiterate & 39 (32.5) & 0 \\
\hline$<S_{S C}^{*}$ & $20(16.7)$ & 0 \\
\hline SSC & $29(24.2)$ & 0 \\
\hline $\mathrm{HSC}^{\dagger}$ & $15(12.5)$ & 0 \\
\hline $\begin{array}{l}\text { Graduate and } \\
\text { above }\end{array}$ & $14(11.7)$ & $65(54.2)$ \\
\hline Post-graduation & $3(2.5)$ & $55(45.8)$ \\
\hline \multicolumn{3}{|l|}{ Working status } \\
\hline Working & $36(30)$ & 100 \\
\hline Not working & $84(70)$ & 0 \\
\hline
\end{tabular}

\begin{tabular}{lcc}
\hline \multicolumn{3}{l}{ Table 2: Grading of knowledge } \\
\hline Grading of knowledge & $\begin{array}{c}\text { General } \\
\text { population } \\
(\mathbf{n = 1 2 0})(\%)\end{array}$ & $\begin{array}{c}\text { Medical } \\
\text { personnel } \\
(\mathbf{n}=120)(\%)\end{array}$ \\
\hline Zero knowledge & $81(67.5)$ & 0 \\
Poor knowledge & $30(25)$ & 0 \\
Average knowledge & $3(2.5)$ & $9(7.5)$ \\
Good knowledge & $6(5)$ & $41(34.2)$ \\
Very good knowledge & 0 & $70(58.3)$ \\
\hline
\end{tabular}


Table 3: Practice of cervical cancer screening

\begin{tabular}{lcc} 
Pap test & $\begin{array}{c}\text { General population } \\
(\mathbf{n}=\mathbf{1 2 0})(\mathbf{\%})\end{array}$ & $\begin{array}{c}\text { Medical personnel } \\
(\mathbf{n}=\mathbf{1 2 0})(\%)\end{array}$ \\
\hline Ever done & $30(25)$ & $21(17.5)$ \\
Never done & $90(75)$ & $99(82.5)$ \\
HPV* vaccination & $2(1.7)$ & $22(18.3)$ \\
received & & \\
*HPV: Human papilloma virus & &
\end{tabular}

Counseling was done for the women who never underwent screening test. In general population group, 55.6\% (50 women out of 90) had positive attitude for screening while in medical personal group, 61.6\% (61 women out of 99) women had positive attitude. The main cause of not accepting the screening of cancer cervix in both the groups was embarrassment. The main source of knowledge in general population was medical personnel followed by mass media such as television, print media, and newspapers.

\section{DISCUSSION}

Cervical cancer is one of the leading causes of morbidity and mortality among women in India. Poor knowledge and attitude towards cervical cancer screening and HPV vaccination are important causes of low utilization of these services. This has been observed not only among general population but also among women of medical profession.

In the present study, we observed that $67.5 \%$ women in general population had zero knowledge and $25 \%$ had poor knowledge, and in medical personnel group, 93\% women had good and very good knowledge. Jain et al., found that the number of women aware of cervical cancer and screening tests was $86 \%$ in their study. ${ }^{6}$ Swapnajaswanth et al., found the similar status of knowledge in medical personnel group. ${ }^{7}$ This signifies that care givers are having good knowledge and they can be a good source of knowledge for general population. The source of knowledge in general population is medical personnel which is similar to the study by Hoque. ${ }^{8}$

In this study, we found that $75 \%$ women from general population group never had pap smear and neither $98 \%$ women were vaccinated whereas in medical personnel group, despite of having knowledge of 100\%, 82.5\% women never had pap smear and only $18 \%$ were vaccinated. The studies by Swapniljaswanth et al., and Tran et al., had found cervical cytological screening in about $26 \%$ and $13 \%$, respectively. ${ }^{7,9}$ Thus, it showed that knowledge in medical personnel group had no or very less effect on their practice.

In the general population group, the main reasons for never willing to undergo cervical screening test included no symptoms in 60\% $(\mathrm{n}=24)$ and embarrassment in 35\% $(n=14)$ whereas in the medical professional group, the main reasons were embarrassment in 68.4\% $(n=26)$ and no symptoms in $15.8 \%(n=6)$. Swapnajaswanth et al., noted that the most common reason for not practicing screening test was absence of symptoms (31\%), and the second common reason was the subjects felt they were not at risk $(29 \%)^{7}$

In the present study, more number of women in the general population group had screening (25\% vs. $17.5 \%)$, but more number of women in the medical profession group changed their attitude after proper counseling (61.6\% vs. $55.6 \%$ ).

In the index study, there was wide discrepancy in the knowledge and practice in both the groups. Other similar studies also reported gap in knowledge and practice. ${ }^{10,11}$ This gap is more prominent in medical personnel group who are the main source of information for the women in the general population. Thus, health care professionals need to be sensitized first for undergoing cervical cancer screening because of their essential role in the implementation of any future screening programs.

\section{Limitation of the study}

The present study has small sample size. On the other hand, the strength is that two different groups (general population and medical personnel) have been studied simultaneously for KAP regarding carcinoma cervix and its screening.

\section{CONCLUSION}

The study concludes that effective information, education and communication strategies are required in both the groups to bridge the gap of knowledge and the actual screening practice. It is necessary that health care providers should have adequate knowledge and a positive attitude towards screening so that they can motivate the general population for the same.

\section{ACKNOWLEDGMENT}

The authors would like to thank the doctors, staff and also the subjects for their consent to participate in this study.

\section{REFERENCES}

1. Ferlay J, Shin HR, Bray F, Forman D, Mathers $C$ and Parkin DM. Estimates of worldwide burden of cancer in 2008: GLOBOCAN 2008. Int J Cancer. 2010;127(12):2893-2917. https://doi/10.1002/ijc.25516

2. Forman D, de Martel C, Lacey CJ, Soerjomataram I, LortetTieulent J, Bruni L, et al. Global burden of human papillomavirus and related diseases. Vaccine. 2012;30(Suppl 5):F12-F23. 
https://doi.org/10.1016/j.vaccine.2012.07.055

3. Sung H, Ferlay J, Siegel RL, Laversanne M, Soerjomataram I, Jemal A, et al. Global cancer statistics 2020: GLOBOCAN estimates of incidence and mortality worldwide for 36 cancers in 185 countries. CA Cancer J Clin. 2021;71(3):209-249.

https://doi.org/10.3322/caac.21660

4. Roy B and Tang TS. Cervical cancer screening in Kolkata, India: Beliefs and predictors of cervical cancer screening among women attending a women's health clinic in Kolkata, India. J Cancer Educ. 2008;23(4):253-259.

https://doi.org/10.1080/08858190802189105

5. Cronje HS. Screening for cervical cancer in the developing world Best Pract Res Clin Obstets Gynaecol. 2005;19(4):517-529. https://doi.org/10.1016/j.bpobgyn.2005.02.005

6. Jain SM, Bagde MN and Bagde ND. Awareness of cervical cancer and Pap smear among nursing staff at a rural tertiary care hospital in Central India. Indian J Cancer 2016;53(1):63-66. https://doi/10.4103/0019-509X.180823

7. Swapnajaswanth M, Suman G, Suryanarayana SP and Murthy NS. Perception and practices on screening and vaccination for carcinoma cervix among female healthcare professional in tertiary care hospitals in Bangalore, India. Asian Pac J Cancer Prev. 2014;15(15):6095-6098.

https://doi/10.7314/apjcp.2014.15.15.6095

8. Hoque ME. Cervical Cancer awareness and preventive behaviour among female university students in South Africa. Asian Pac J Cancer Prev. 2010;11(1):127-130.

9. Tran NT, Taylor R, Choe SI, Pyo HS, Kim OS and So HC. Knowledge, attitude and practice (KAP) concerning cervical cancer and screening among rural and urban female healthcare practitioners in the democratic people's republic of Korea. Asian Pac J Cancer Prev. 2011;12(11):3023-3028.

10. Addah AO, Ojule JD and Fiebai PO. Knowledge, attitude and practice of cervical cancer screening-Papanicolaou test (Pap smear) among female health care providers in Port Harcourt. Afr J. 2012;6(1):74-80. https://www.ajol.info/index.php/phmedj/article/view/74002

11. Shekhar S, Sharma C, Thakur S and Raina N. Cervical cancer screening: Knowledge, attitude and practices among nursing staff in a tertiary level teaching institution of rural India. Asian Pac J Cancer Prev. 2013;14(6):3641-3645. https://doi/10.7314/apjcp.2013.14.6.3641

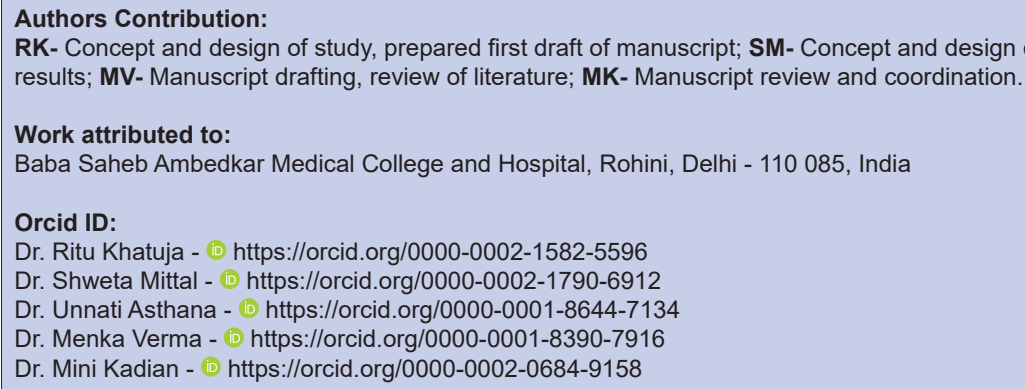

Source of Funding: None, Conflicts of Interest: None. 